\title{
CINEMA E UTOPIA: UMA ESPERANÇA POSSÍVEL PARA A AMÉRICA LATINA
}

\section{CINEMA AND UTOPIA: A POSSIBLE HOPE FOR LATIN-AMÉRICA}

O livro escrito por Bruno Vilas Boas Bispo ${ }^{1}$ analisa a trilogia ${ }^{2}$ da Batalha do Chile do cineasta Patrício Guzmán buscando compreender as representações utópicas presentes nos filmes. O autor tem como horizonte a investigação dos elementos de utopia da realidade chilena expressas pela obra cinematográfica, a qual destaca o processo do governo de Salvador Allende, na década de 1970.

Dividido em quatro capítulos: introdução; cinema e realidade social; a esperança enquanto perspectiva de construção de mundo; a batalha do Chile: a luta de um povo sem armas. O livro destaca ao longo da sua análise dois elementos centrais, primeiro, a relação da arte com a sociedade e a sua potência de representar à objetividade, segundo, a capacidade que o cinema possui de viabilizar narrativas utópicas. Essas duas concepções percorrem toda a obra de acordo com a temática investigada em cada capítulo, isso, demonstra um encadeamento na interpretação do fenômeno estudado no qual produz ao leitor uma fluidez na leitura.

$\mathrm{Na}$ introdução, o autor descreve o caminho trabalhado no livro destacando os elementos estudados na pesquisa e que são centrais para o entendimento da interação entre arte e sociedade, utopia e cinema, por exemplo, a relação dialética entre subjetividade e objetividade do ponto de vista da criação artística, das contradições e modificações sociais presentes na vida cotidiana que implicam algumas características do processo analítico da obra:

a. decomposição (consiste na interpretação do objeto fílmico a partir das unidades técnicas e da formação de uma tese final sobre os fenômenos estudados);

b. contexto histórico de formação do filme;

Doutorando em Ciências Sociais pelo PPGCS-UFBA, com pesquisa em curso acerca das Representações Utópicas do Cinema Novo Latino Americano. Mestre em Ciências Sociais pelo Programa de Pós-Graduação em Ciências Sociais da Universidade Federal da Bahia. Possui graduação em Licenciatura e Bacharelado em Ciências Sociais pela Universidade Federal da Bahia (2013). Participa do grupo Representações sociais: arte, ciência e ideologia desde 2009, sediado na Faculdade de Filosofia e Ciências Humanas (UFBA).

2 Insurreição da Burguesia (1975); O Golpe de Estado (1977) e O Poder Popular (1979). 
c. desenvolvimento das relações de produção;

d. mudança na forma e conteúdo do cinema devido ao avanço tecnológico

Um dos pontos chaves da obra é a facilidade de compreender o texto devido à forma como foi construída a interpretação da utopia a partir da trilogia, essa conexão produziu duas percepções: 1) as categorias utilizadas para empregar a análise fílmica foram articuladas a partir de um rigor teórico-metodológico no qual conseguiu dialogar com leitores não afeitos ao tema; 2) o objeto empírico escolhido apresenta uma experiência histórica da América Latina atemporal no sentido utópico.

Continuarei a tocar na perspectiva de que o livro é capaz de dialogar com variados tipos de leitores porque essa é uma das problemáticas encontradas em diversas obras ${ }^{3}$ fruto de pesquisa científica, mas as Imagens de uma utopia latino-americana: a batalha do Chile, filme de Patrício Guzmán rompe com essa lógica oferecendo ao público uma sensação que vai além das concepções teóricas, objetivas e artísticas elaboradas na obra nos proporcionando uma investigação da realidade social chilena capaz de aguçar os nossos sentimentos em torno da esperança de um futuro sem grilhões.

O primeiro capítulo do livro é trabalhado a relação entre o cinema e a sociedade buscando evidenciar os elementos de realidade presentes na cinematografia, para isso, é abordado através de alguns teóricos como Lukács, Adorno, Hegel e Benjamin os conteúdos em volta da representação, estética, subjetividade e objetividade, além disso, são discutidas as questões em torno do cinema documentário e as suas transformações ocorridas na história. O segundo, "A esperança enquanto perspectiva de construção de mundo", ocorre à fundamentação teórica a partir de Bloch ${ }^{4}$ da ideia de utopia enquanto possibilidade de modificação real das condições materiais.

Ambos têm como horizonte a fundamentação teórica, mas categoricamente procuram analisar, por via do seu objeto, ideias que se relacionem entre si, a exemplo, da concepção de utopia utilizada por Bloch para interpretar as representações no filme. Bloch emprega o conceito em conformidade com o mundo concreto sendo passível de transformações reais e não como uma ilusão de um futuro risível, desse modo, a investigação das imagens fílmicas de um determinado período histórico onde as forças sociais estão em constante fluxo

\footnotetext{
Nesse trecho, é destacada a capacidade de alcance do livro no sentido de produzir conhecimento sem restringir a sua potência somente ao campo científico.

4 "No entanto, como pretendemos compreender como os documentários de Guzmán representam um momento pleno de utopia e esperança no Chile, abordaremos a teoria construída por Ernst Bloch acerca da utopia e da esperança, principalmente em sua obra O Princípio Esperança. Tal discussão teórica visa balizar os conceitos citados - como utopia e esperança-como referência categórica para a análise estética, o que nos permitirá atuar com mais rigor na análise fílmica” (BISPO, 2019, p. 55).
} 
construindo relações sociais inovadoras e mudando as estruturas de poder proporcionam anseios utópicos, os quais são materializados pelas ações dos variados grupos e sujeitos em movimento nessa conjuntura sócio histórica.

No último capítulo do livro é trabalhada a análise fílmica. Quatro pontos são significativos para compreender a interpretação do autor a respeito da obra cinematográfica: a) a interpretação das representações utópicas nas três películas buscando a particularidade do paradigma não somente no conteúdo representado pelo documentário, mas na forma do filme; $b$ ) a explicação do modo como os recursos técnicos da trilogia possuem uma potência para expressar alguma ideia; c) a relação dialética entre subjetividade e objetividade; d) a análise de uma experiência histórica relacionando estética, utopia, sociedade e política.

O autor inicia ${ }^{5}$ com uma descrição sobre a situação política chilena e as condições materiais que levaram o país para um processo de transformação social (reforma agrária, nacionalização de empresas, aumento salarial, fortalecimento da unidade com os variados setores da esquerda, crescimento da participação política da classe trabalhadora, etc) rompendo com alguns elementos do modo de produção capitalista. Em seguida, nas três subseções, são investigadas as partes do documentário e da maneira como a utopia foi representada.

$\mathrm{Na}$ análise da parte ${ }^{6} \mathrm{I}$ do documentário é destacada através da burguesia chilena a utilização de diversos artifícios para desestabilizar o governo de Salvador Allende, a exemplo, das greves patronais e dos bloqueios econômicos com o apoio dos E.U. A, além disso, apresenta a forma como Patrício Guzmán construiu uma crítica social, por intermédio, da estética da obra. Para isso, o autor aponta a função exercida no decorrer da montagem, na qual a contraposição $0^{7}$ de dois eventos representados pela junção das imagens tem o potencial de indicar um determinado posicionamento ${ }^{8}$ a respeito da realidade chilena.

A parte ${ }^{9}$ II, apontada pelo autor como a que traz menos elementos utópicos, representa o processo do golpe de Estado e a articulação realizada pelos membros de partidos de direita e extrema-direita junto com as forças armadas e diversas frações da burguesia para destituir Salvador Allende da presidência.

\footnotetext{
O último capítulo do livro é composto por quatro subseções sendo as três últimas referentes a trilogia do documentário: a) caminhos da via chilena ao socialismo: um preâmbulo histórico; b) a insurreição da burguesia; c) o golpe de Estado; d) o poder popular.

6 Insurreição da Burguesia (1975).

7 No sentido de uma cena representar indivíduos que apoiam o governo de Salvador Allende e as mudanças realizadas para a classe trabalhadora e a outra se contrapor apresentando grupos de pessoas apoiando o Partido Nacional, e com ojeriza da situação atual do país culpabilizando a "governabilidade marxista" da União Popular.

8 A prerrogativa de representar o conflito político gerado pelo acirramento de classe no Chile apontando a formação de forças fascistas e imperialistas contra a organização dos trabalhadores, camponeses e movimentos de esquerda.

O Golpe de Estado (1977).
} 
Nessa segunda parte do documentário, o autor ${ }^{10}$, chama a atenção para como a classe trabalhadora chilena estava consciente de um possível ataque ao governo, demonstrando está disposta a lutar para defender os direitos conquistados.

Entretanto, o autor, não realiza a interpretação de um momento singular expresso pela obra cinematográfica onde a utopia é barrada através da ditadura civil-militar, encerrando a esperança de um futuro utópico. Ao final da segunda parte do documentário é representado três generais das forças armadas anunciando o novo governo depois de assassinar Allende no palácio da La Moneda, em 11 de setembro de 1973. No discurso dos ditadores fica evidente o nível ideológico manifestado para a população chilena a respeito do Estado que foi consolidado, a exemplo, do fechamento do Congresso e de uma suposta doutrinação marxista exercida durante o governo anterior. Nesse limiar, a representação fílmica destaca o ataque à construção de uma utopia e do seu desenvolvimento concreto.

Outro ponto particular que potencialmente pode representar uma perspectiva utópica não é analisado no livro: o discurso de Salvador Allende no momento do bombardeio ao palácio da La Moneda. Esse período histórico representado pelas imagens aponta para a ideia de um futuro construído concretamente, porque com os devidos equívocos tomados pelo governo Allende de não radicalizar a luta social a sua última fala antes da sua execução surge como uma pulsão, um sonho diurno ${ }^{11}$ exterminado pelas forças da opressão, mas vivos pelo poder da esperança.

Na última subseção do livro é realizada a análise da parte fina ${ }^{12}$ do documentário destacando as representações utópicas a partir do processo de consolidação e organização do poder popular, surgido em contraposição aos bloqueios e greves patronais operacionalizadas pelos setores da burguesia e dos partidos de direita e extrema-direita. Segundo o autor essa é a representação da trilogia na qual proporciona mais elementos utópicos, porque apresenta o desenvolvimento de um futuro construído pelos anseios da classe trabalhadora e do modo de articulação e consciência política produzida objetivamente.

Todavia, o livro as Imagens de uma utopia latino-americana: a batalha do Chile, filme de Patrício Guzmán possibilita ao leitor a experiência de entender a realidade social através da arte e compreender que a vida cotidiana não é apenas a rotina de todos os dias, mas o constante processo de afetação articulados pelos

\footnotetext{
10 Bruno Bispo.

11 "Entendendo o sonho diurno como prelúdio da arte, Bloch aponta que ele visaria, de maneira significativa, a melhoria do mundo, de forma utópica. O sonho diurno teria em si o elemento da autoexpansão com vistas a um mundo melhor. Ao utilizar-se desse elemento como matéria-prima, a arte estaria carregada de imagens de um melhor possível [...]" (BISPO, 2019, p. 78).

12 O Poder Popular (1979).
} 
indivíduos, instituições, trabalho e o mundo interior habitado nos sujeitos, os quais são modificados e modificam a história.

\section{REFERÊNCIAS}

BISPO, Bruno Vilas Boas. Imagens de uma utopia latino-americana: a batalha do Chile de Patrício Guzmán. Curitiba: Appris, 2019.

BLOCH, Ernst. O Princípio Esperança. Rio de Janeiro: EdUERJ: Contraponto, 2005. (v 1).

\section{REFERÊNCIAS AUDIOVISUAIS}

LA BATALLA DE CHILE I: La Insurrección de la Burguesía. Direção: Patrício Guzmán. Produção: Chris Marker. Roteiro: Patrício Guzmán, Pedro Chaskel, Julio García Espinosa, Federico Elton, Jose Bartolome. Elenco: Salvador Allende, Abílio Fernandéz (narrador). Chile/Cuba/Venezuela: Equipe Tercer Año/ Atacama Productions, 1975. (100 mim), son., $P \& B$.

LA BATALLA DE CHILE II: El golpe de Estado. Direção: Patrício Guzmán. Produção: Chris Marker. Edição: Pedro Caskel. Elenco: Abílio Fernandéz (narrador). Chile/Cuba/ França: Equipe Tercer Año/ Atacama Productions, 1977. (90 mim), son., P\&B.

LA BATALLA DE CHILE III: El Poder Popular. Direção: Patrício Guzmán. Produção. Roteiro: Patrício Guzmán. Elenco: Abílio Fernandéz (narrador). Chile/Cuba/Venezuela: Equipe Tercer Año/Atacama Productions, 1979. (82 mim), son., P\&B. 
